\title{
Patrimônio, Cidade e o Papel do Desenho Urbano*
}

\author{
Heritage, the City and the Role of Urban Design \\ Antonio Capestro \\ Università degli Studi di Firenze, Italia \\ antonio.capestro@unifi.it
}

Patrimonio, Ciudad y el Papel del Diseño Urbano

DOI: https://doi.org/10.18472/cvt.21n1.2021.1921

Redalyc: http://www.redalyc.org/articulo.oa?

$\mathrm{id}=115466307006$

Recepción: 12 Abril 2020

Aprobación: 12 Febrero 2021

\section{Resumo:}

A conservação e valorização do Patrimônio Urbano constitui um dos desafios mais significativos dos últimos cinquenta anos, assumindo uma considerável importância tanto no sentido da preservarção e salvaguarda de valores compartilhados como na valorização da herança do passado enquanto recurso. Junto ao binômio clássico - e já bastante debatido - do projeto do patrimônio, o artigo propõe outro enfoque: a importância do patrimônio do projeto, uma vez que aquilo que se considera como Patrimônio é produto de um processo dinâmico que transfigura as permanências do passado para renovar sua contribuição no futuro. Ao não intervir sobre o patrimônio, estamos contradizendo sua própria essência. $\mathrm{O}$ artigo apresenta uma abordagem teórica que alimenta e é alimentada pela prática, focando na noção de patrimônio do projeto tanto na dimensão da pesquisa acadêmica quanto no desenho urbano e na intervenção sobre/no espaço, buscando um equilíbrio entre a preservação e uma constante evolução de usos e fruições que não dependem apenas de seu contexto geográfico e social, mas de fluxos mundiais, como o do turismo.

Palavras-chave: Patrimônio, Cidade, Desenho Urbano.

\section{ABstract:}

The preservation and valorization of urban heritage has proven to be one one the most significant challenges or the last fifty years, acquiring worldwide relevance both in terms of the conservation of shared values and in the acknlowedegmente of the value of heritage as a resource. Alongisde the wellknown - and widely debated - notion of heritage design, the paper proposes another focus: the relevance of design heritage, since what is considered as heritage is the product of a dynamic process that transfigures the remains of the past and renew its contribution to the future. When we do not intervene on heritage, we are contradicting its very essence. The paper presentes a theoretical approach that feeds and it is fed by practice, focusing on the notion of design heritage in academic research and urban design and searching for a balance between conservation and a constant evolution of uses and fruitions that do not depend only on local geographical and social contects, beinge affected by worldwide dynamics like those of global tourism.

KeYwORDS: Heritage, City, Urban Design.

\section{RESUMEN:}

La conservación y valoración del Patrimonio Urbano es uno de los retos más importantes de los últimos cincuenta años, asumiendo una importancia considerable tanto en términos de preservar y salvaguardar los valores compartidos como en la valoración del patrimonio del pasado como recurso. Junto al clásico - y ya muy debatido - binomio del proyecto del patrimonio, el artículo propone otro enfoque: la importancia del patrimonio del proyecto, ya que lo que se considera patrimonio es producto de un proceso dinámico que transfigura las permanencias del pasado e renueve su contribución para el futuro. Al no intervenir en el patrimonio, estamos contradiciendo su esencia misma. El artículo presenta un enfoque teórico que nutre y és nutrido por la práctica, centrándose en la noción de patrimonio del proyecto tanto en la dimensión de la investigación académica y en el diseño urbano como en la intervención sobre / en el espacio, buscando un equilibrio entre la preservación y una evolución constante. de usos y fruiciones que no dependen solo de su contexto geográfico y social, sino de flujos globales como el turismo.

Palabras Clave: Patrimonio, Ciudad, Diseño Urbano. 


\section{INTRODUÇÃO}

A conservação e valorização do Patrimônio Urbano constitui um dos desafios mais significativos dos últimos cinquenta anos, assumindo uma considerável importância nas políticas públicas mundiais tanto no sentido da preservarção e salvaguarda de valores compartilhados como na valorização da herança do passado enquanto recurso. Neste novo enquadramento, o significado de Patrimônio amplifica as noçóes fundamentais de tutela e conservação para ressaltar a importância da sua valorização como recurso em um sistema complexo, dotado de energias capazes de 'regenerarem-se' e também de 'regenerar'.

Junto ao binômio clássico - e já bastante debatido - do projeto do patrimônio, surge ainda outra questão: a importância do patrimônio do projeto, compreendido como o processo que levou àquelas transformações - uma vez que aquilo que gerou o Patrimônio é um forte planejamento que transfigurou as permanências do passado, modificando-as para renovar sua contribuição no futuro. O conhecimento acerca do patrimônio sublinha este aspecto intrínseco da 'transformação' - ao não intervir sobre o patrimônio, estamos contradizendo sua própria essência.

Isto se torna mais significativo uma vez que as cidades de hoje devem, por um lado, salvaguardar a persistência física e cultural do sentido do lugar, estando, por outro lado, em uma constante evolução de usos e fruições que não dependem apenas de seu contexto geográfico e social, mas de fluxos mundiais, como: o do turismo; o setor imobiliário, que submetido às tensões decorrentes de novos ritos está sujeito à revisão de seus planos de uso; a conservação do património histórico urbano que, para se defender de fluxos incontroláveis, corre o risco de se congelar, perdendo assim a conotação de um bem comum de fruição pública; e, por último. mas não menos importante, a atual crise sanitária que exige uma outra reconsideração do sistema cidade, que corre o risco de se tornar frágil por não conseguir reagir a essas solicitações.

Se isolamos o lugar como monumento ou conjunto de monumentos, corremos o risco de contradizer sua natureza de "organismo dinâmico" (Bokova, 2012), inibindo qualquer capacidade de resiliência.

Se recuperamos a parática projetual que, por sua natureza, induz uma transformação, muitas vezes a apresentando como visão e não como simples adequação funcional, reforçamos a identidade do próprio patrimônio através de respostas autenticamente modeladas na contemporaneidade, mas com raízes no passado (Capestro, 2019, p. 1737).

É sob esta ótica que se articulam as reflexões que emergiram no contexto da minha experiência com a pesquisa, o ensino e a prática na área do Desenho Urbano.

\section{Pela renovação da Cultura de projeto do Patrimônio}

O papel econômico e social das cidades históricas está sujeito a transformações de seus usos e funções, nem sempre e não apenas determinadas pelos seus habitantes, mas também, sobretudo, por fatores definidos em escala global. Este aspecto havia sido considerado, nos últimos vinte anos do século passado, como uma possibilidade positiva para se reafirmar a identidade dos lugares em um sistema de relações globais - uma espécie de Renascimento do terceiro milênio. Quando havia o temor da necrose urbana, o debate acadêmico se concentrava em uma nova vitalidade para a cidade e a arquitetura, graças às oportunidades oferecidas pelas tecnologias de comunicação. Em particular, destacava-se que a globalização seria uma oportunidade imperdível para a transmissão da diversidade, o que poderia valorizar a identidade das cidades e comunidades.

Infelizmente, ao longo do tempo se perdeu um dos termos essenciais do binômio (o respeito por esta identidade que, em uma escala global, é multicultural e o sentido de pertencimento) e que a globalização sobrevivente tenha arriscado - ou corrido o risco de - nos conduzir ao niilismo das referências mais essenciais para se habitar um lugar, ao nos aproximar da padronização, da internacionalização, da espetacularização, até chegar à globalização como ausência homologada e incondicional de identidade e raízes. 
É neste contexto que as cidades, sobretudo de tradição cultural-histórico-artística, têm muitas vezes convertido a sua identidade em apelo para serem transformadas em ícone do mundo cultural com um efeito de marca (brand) totalmente desvinculado do contexto e dos seus componentes estruturais como o genius loci e a identidade da comunidade.

Para os arquitetos, um dos principais aspectos através dos quais é possível apreender a origem da harmonia da cidade histórica é, sem dúvida, dado pelo ecoar à distância, e em contextos diversos, dos mesmos cânones estéticos, de um sentido análogo de ordem e medida, que sempre representaram a alma da cidade. Este admirável equilíbrio, que sempre alimentou a complexidade das transformações urbanas segundo um princípio de modificação evolutiva, parece ter sofrido recentemente uma parada traumática: a certa altura, como que arrebatados por uma amnésia misteriosa, nos voltamos para outro lugar (Capanni, 2019, p. 15).

Devemos somar a isto os novos desafios que cidades, comunidades e o meio ambiente têm que enfrentar: processos de urbanização rápida e descontrolada, fragmentação social e espacial, deterioração da qualidade do ambiente urbano e seus contextos territoriais, perda de espaços e serviços públicos, infraestrutura inadequada, novas formas de pobreza, isolamento social e novos conflitos, um risco crescente de desastres climáticos e, não menos importante, a atual crise de saúde.

A cidade, tanto nas áreas 'historicizadas' como nas periferias, deve refletir hoje sobre o papel e a figura simbólica que deverá assumir, sobretudo porque, desde os anos 1980, as transformações referem-se tanto às dimensões imateriais quanto às dimensões materiais. $\mathrm{O}$ termo crescimento, confrontando-se com o termo crise, começa a adquirir significados particulares, trilhando o caminho da mudança sem crescimento.

Isto implicou a transformação do existente, reaproveitamento, recuperação, mas também a consideração de recursos extra moenia que contemplavam, além dos sistemas estruturais físicos, também a valorização de recursos e interesses a serem reformulados na cidade que, nesta lógica, assumem um caráter diverso de centralidade que não é mais um atributo da localidade mas de uma política urbana atenta às regras de cooperação e parceria (Capestro, 2012, p. 23)

E, agora mais do que nunca, para a inclusão da diversidade cultural como um enriquecimento da identidade local.

Destas consideraçóes emerge a oportunidade de atuar assumindo um posicionamento claro sobre a temática do Patrimônio e sobre os aspectos básicos e essenciais de seu projeto, conforme destacado pela Unesco[1]:

- Cidades com natureza orgânica e dinâmica. "As cidades são organismos dinâmicos. Não há uma única cidade no mundo que não tenha mudado seu caráter 'original': esta característica é por sua natureza destinada a acompanhar as mudanças na sociedade” (Bokova I. G. 2012);

- Patrimônio que se amplia como um sistema complexo.

Deixando de ser considerado um monumento estático ou um conjunto de lugares, arquiteturas, culturas e obras individuais, que muitas vezes são fragmentos suspensos e estranhos à lógica sistêmica da cidade, o Patrimônio recupera sua ontologia como um 'ecossistema' de valores materiais e imateriais que ampliam o sentido do centro histórico, com todos os seus componentes físicos (emergências e tecido), num reconhecimento mais amplo da importância dos processos sociais, culturais e econômicos (Capestro 2019, p. 29).

Ações de proteção da "Paisagem Urbana Histórica" através da construção de alianças estratégicas e dinâmicas entre os diversos atores da cena urbana (poderes públicos que administram a cidade, os atores que nela atuam, os cidadãos que nela habitam).

Entre as ações estão: apoiar políticas em nível local para a implementação de princípios e diretrizes compartilhados internacionalmente; levantamentos e mapeamento de recursos naturais, culturais e humanos; processos participativos; projetos; monitoramento e compartilhamento de boas práticas (Capestro, 2019, p. 30).

Uma vez que o sentido de Patrimônio e sua substância coincidem com um patrimônio físico, social, cultural e econômico, definido por valores que, em sua diversidade, produziram um valor novo, o patrimônio 
passa a ser tudo o que foi gerado pelo próprio patrimônio e que pode construir novas formas de patrimônio nas expectativas de quem os vive. Nesse sentido, a lista de componentes que definem o patrimônio material e imaterial, a serem interpretados para o seu projeto, é uma lista aberta, nunca previsível, certamente implementável. Assim como as variáveis de projeto podem ser repensadas de forma ampliada e articulada, não cristalizadas em soluções e esquemas pré-definidos, mas abertas a uma definição de um conceito diferente que, assumindo como ponto de partida o conhecimento e a memória do lugar, as internaliza em uma nova história inclusiva e sustentável.

A importância do Patrimônio do projeto, compreendido como um processo de transformações tanto do caráter morfológico, funcional e cultural como também de formas renovadas de interpretar as permanências para transportá-las para o futuro, preocupa todos os atores da cena urbana (projetistas, gestores, atores, cidadãos). Agora, mais do que nunca, estes atores se perguntam como é apropriado intervir no patrimônio, resgatando uma cultura de projeto como ação consciente para obter um resultado que também introduza o conceito de 'tutela' como ato de responsabilidade, uma atitude ética. Como a cultura da cidade é feita de memória, mas também de transformação, é portanto desejável referir-se às estratificações históricas para se reposicionar no presente, aqui e agora, e dar a nossa contribuição no futuro.

O Projeto, enquanto ação consciente de regeneração do patrimônio, torna-se ele próprio patrimônio porque é um instrumento fundamental para a sua proteção - se partirmos do pressuposto de que o conceito de patrimônio é dinâmico e complexo. $\mathrm{O}$ projeto, de fato, reinterpreta o patrimônio como um sistema complexo, resgata os fios narrativos da história, reconcilia-os com os desejos de uma sociedade hoje multicultural e com o genius loci do contexto para compartilhar esses processos de transformação de modo que seja um 'bem comum' e volte a ser o lugar das relações de identidade em uma sociedade definida a uma escala global. No sentido de preservar e valorizar o patrimônio, portanto, é necessário pensar em transformálo, porque a transformação, que implica um projeto, é inerente à sua natureza, que comporta características de 'identidade', 'integridade' e 'autenticidade' que são testemunho de um processo dinâmico baseado nas interações entre urbs e civitas que hoje, em muitos casos, estão muito comprometidas.

De fato, alguns processos de modernização e globalização nos fizeram perder o sentido da cidade, que hoje se caracteriza por uma série de fragmentos suspensos - dispositivos desconectados que perderam a estrutura lógica e sistêmica da cidade. Recuperar o costume do projeto significa reler a identidade daquele fragmento suspenso e reposicioná-lo, recuperando a sua estrutura profunda em uma estrutura lógica afim de a reconciliar com os seus cidadãos, tentando assim reconstruir a relação entre urbs e civitas porque, como argumenta Renzo Piano: "A arquitetura - e eu acrescentaria a cidade - é a expressão de uma arte cívica, deve fazer felizes as pessoas que devem aprender a adotá-la e amá-la”[2].

Aprender a recuperar esse sentimento de pertencimento à cidade como organismo que, como já foi dito, não se congela, mas se transforma, talvez pudesse nos permitir posicionar-nos de forma mais adequada para responder à atual crise do setor de saúde - uma demanda obrigatória que não podemos ignorar. No entanto, esperamos que esta crise possa ser uma oportunidade de recuperação para uma cultura de projeto "sincera" que pode desviar a atenção para relações fundamentais, como aquelas entre a urbs e a civitas.

Este é precisamente o significado do ciclo de conferências online internacionais "La Città / Le Città" [3], realizado de maio a julho e de setembro a dezembro de 2020 para tentar formular uma pergunta precisa antes de imaginar respostas sobre um assunto tão complexo quando debatido, considerando que hoje, em plena emergência, a cidade/as cidades (la città/le città) em reclusão, foram despojadas do barulho dos mais variados ícones que se apresentavam como essenciais diante de nós. Embora silenciosas, pela sua estrutura de matéria, de surpreendente beleza e valor semântico, com a sua presença, a cidade/as cidades parecem convidar-nos a escutar os campos abertos da investigação, dos quais há muito tempo nos distraímos.

Expoentes do mundo da pesquisa, cultura, política, arte, trabalho e comunicação foram entrevistados para apresentar seus pensamentos e iniciar um debate em um espaço virtual de reflexão compartilhada. Os temas da discussão concentraram-se nas formas como a cidade terá de ser repensada, quais as ideias, políticas e as 
estratégias para imaginar um futuro próximo e sustentável para todos. Especificamente, surgiram reflexões sobre como se transformarão o espaço e a experiência urbana e qual será o papel do Desenho Urbano na configuração de novas visões no contexto pós-pandêmico - uma vez que a cidade/ as cidades esperam por um enfoque diferente sobre novas formas de habitar integrando arquitetura, cidades, territórios e planeta [4].

O ciclo, concebido como uma "sala de estar urbana", visa estimular ideias, visões e leituras, e funcionar como uma incubadora na qual se ativam estratégias voltadas para novas oportunidades e não para ações remediadoras[5]. Os dois primeiros encontros, "Comunidades Resilientes" e "Projetar para os Bens Comuns", exploraram tais temas com os curadores do pavilhão da Itália nas Bienais de Veneza de 2016 e 2020.

\section{Conferência}

O papel econômico e social das cidades históricas está sujeito a alterações de uso e funções, nem sempre e não apenas determinadas pelos seus habitantes, mas sobretudo também por fatores definidos em escala global. Esse aspecto havia sido considerado nos últimos vinte anos do século passado como uma possibilidade positiva de reafirmar a identidade dos lugares em um sistema de relações globais, em uma espécie de Renascimento do terceiro milênio.

\section{Conferência}

Massimo Lepore e Simone Sfriso, do estúdio TAM (curadores da bienal de 2016) participaram de uma conversa sobre "bens comuns" e "projeto". A Cidade, neste sentido, pode conter a marginalização e a exclusão e se tornar um motor de novas visões, um poderoso meio de comunicação, uma ferramenta pela qual muitas áreas externas da cidade podem reivindicar direitos, progresso, oportunidade e inclusão.

A arquitetura, com suas competências específicas, pode ajudar a disseminar e efetivar os princípios da sociabilidade, participação, saúde, integração e legalidade, em qualquer lugar e em qualquer escala. Encarnando estes princípios, a arquitetura deste milênio terá cada vez mais que enfrentar e encontrar respostas aos desafios que a cidade e o ambiente apresentam não só aos arquitetos, mas a todos os designers mais responsáveis do futuro próximo.

\section{Conferência}

Depois do ponto de vista dos curadores do Pavilhão Itália da Bienal de Arquitetura de Veneza 2016 e 2020 sobre os temas da "Comunidade Resiliente" e do "Projeto de bens comuns", o ciclo continuou com um terceiro encontro sobre o tema da "Estratégia Cultura", com foco em Florença - cidade emblemática no contexto das transformações atuais. Com Tommaso Sacchi, assessor para a Cultura do Município de Florença, conversamos sobre como a cultura pode se tornar uma estratégia de mudança, partindo de Florença, extraordinária declinação de um patrimônio de recursos. O encontro tratou da questão da importância da comunidade e da cidade como elementos fundamentais para uma construção plural de conscientização e cuidado com um patrimônio comum e a oportunidade de estimular sinergias virtuosas e criativas entre os atores que vão enfrentar a mudança por meio de projetos que consideram a cidade como um laboratório aberto. 


\section{Conferência}

No quarto encontro, "A Cidade Residual", falamos de muitas cidades atuais, residuais porque, embora fisicamente presentes, são vividas “de passagem”, sem cuidados e, portanto, ausentes na construção do sentido de pertencimento do cidadão contemporâneo. O lockdown nos deu a oportunidade de observar esse aspecto com muita clareza. A cidade residual, ou partes dela, são lugares abandonados, 'periferizados' não só por sua localização, mas porque são mal utilizados ou simplesmente deixados por si mesmos. Porém, a cidade residual existe, é feita de materiais, arquiteturas, espaços abertos e fechados, praças, ruas. É 'atravessada', mas não 'habitada' por pessoas e tem muito potencial, seja devido à sua característica de se espalhar dentro de um sistema ou porque subjaz a valiosas situações de campo a serem reinterpretadas.

O encontro falou sobre como reencontrar um protagonismo ponderado na cidade entre lugares esquecidos ou abandonados e lugares que são explorados além de sua capacidade de hospitalidade. Em particular, as reflexões do encontro centraram-se nas formas como o Desenho Urbano pode contribuir para converter a "residualidade" numa oportunidade de resgate, investigando possíveis respostas e estratégias a serem implementadas através do projeto:

- O espaço público como defesa ativa e fio condutor das intervenções sobre as quais aplicar a energia de projeto com as modalidades da acupuntura urbana para uma desejável reverberação, em termos de requalificação, no sistema de assentamento através de ações articuladas e complementares;

- Uma relação renovada entre arquitetura e paisagem e a integração do projeto no contexto através das suas componentes fundamentais - geografia, história dos lugares, características morfológicas - assumidas como elementos geradores;

- A arquitetura como memória e como promessa de oportunidades de identificação relacionais, espaciais e semânticas para todos;

- O papel ativo da comunidade que reacende o fogo da "questão da cidade" e participa de sua reconfiguração.

\section{Conferência}

Os temas tratados neste encontro sobre a "Cidade Residual" introduziram o quinto encontro, que se realizará em breve com foco no tema "O Espaço Social". Ainda faz sentido falar dos atributos físicos do espaço público na era do imaterial e da smart city, no contexto dos desenvolvimentos das cidades do mundo, entre as migrações totais e as crises ecológicas? Como as questões ambientais podem condicionar os espaços públicos? Como a urbs e a civitas podem encontrar momentos de partilha que permitam a todos desenvolver o sentido de pertencimento e identificação pessoal no espaço físico e social? Estas são as questões sobre as quais o debate será articulado.

\section{Possíveis ações e estratégias do Desenho Urbano}

Existem várias 'dimensões' que podem ser exploradas dentro do Projeto Urbano que emergiram do debate sobre o Ciclo "La Citta/Le citta", e muitas formas pelas quais podemos responder em termos de projeto (ou ação) ao fenômeno pandêmico que está caracterizando o nosso tempo.

Comparado com o Urbanismo das últimas décadas, caracterizado em grande parte por ações deterministas que em certa medida delinearam com clareza o destino de uma cidade e da comunidade que a habitava, hoje parece que algo mudou. O Desenho Urbano visa acompanhar ou por vezes ativar processos virtuosos de transformação para a cidade e a comunidade que, de alguma forma, já fazem parte da própria natureza da cidade. Neste sentido, o projeto 'inacabado', mas definido nas suas estratégias, poderá considerar de forma 
mais precisa as diferentes variáveis dos fenômenos de transformação em curso, as necessidades, os desejos dos seus cidadãos e consequentemente ser capaz de centralizar melhor seus objetivos.

Particularmente, entendo como "Dimensões do Desenho Urbano" as complexas relações que se estabelecem entre o espaço e a sociedade e como estas se restitiuem a ambos através das ações que os vários sujeitos, com diferentes níveis e competências, realizam ou podem realizar para resgatar uma qualidade de vida na cidade, permitindo a cada cidadão um processo de identificação no espaço e consequentemente possibilitando a presença do cidadão na "cidade pós digital"[6].

As reflexões apresentadas até agora apresentam a investigação aplicada ao projeto através da didática e testes de campo que pude desenvolver tanto no Departamento de Arquitetura de Florença (DIDA) como através de colaborações com organismos públicos e institutos de investigação nacionais e internacionais. São investigadas, especificamente, as relações que se expressam em um contexto físico que permite aos indivíduos aprimorar sua identidade por meio de experiências, necessidades, desejos. Todas estas relações têm como denominador comum a cidade, como campo de desenvolvimento e afirmação da consciência e de identificação para todos porque a cidade é um patrimônio a recuperar, soma essencial da urbs e da civitas, dois sistemas que se modelam na complexa relação do material e imaterial.

Esse traço comum é expresso tanto na aplicação do método que sigo nos laboratórios de design do Departamento de Arquitetura de Florença quanto na última experiência de pesquisa e projeto aplicada ao patrimônio urbano com foco em Florença. Optei por ilustrar estes dois aspectos porque os considero representativos do estado da arte do meu pensamento como docente e também como arquiteto que vive em Florença, cidade emblemática na questão do projeto do Patrimônio. Florença, de fato uma das mais belas citta\# d'arte do mundo, corre o risco de não se oferecer como campo de experiência para a realização da identidade de seus habitantes permanentes e temporários. Além do valor de sua posição geográfica, mesmo os lugares e monumentos mais importantes correm o risco de ser 'periferizados', delimitados dentro de um ícone cultural que exclui uma experiência consciente. Disto resulta que sua arquitetura e seu tecido urbano não conseguem nem compor uma cidade do mundo, nem uma cidade de cidadãos. Ou seja, há situações lindas que, no entanto, se tornam insuportáveis para todos.

Quanto às diferentes 'dimensões' que podem ser exploradas no âmbito do Projeto Urbano por meio da didática, estas são articuladas por meio de um processo baseado principalmente no ensino que foca em 'fazer' para 'aprender a fazer', onde, no aprender a fazer, algumas passagens são internalizadas de modo a não só aprimorar competências, mas também evidenciar e consolidar ações e relacionamentos. A experiência docente parte dessas questões e se articula por meio de três objetivos:

- Missão - Saber / saber fazer / saber ser arquiteto. O principal objetivo da formação é produzir estímulos para a formação de uma filosofia pessoal de Composição e Projeto de Arquitetura que, partindo do conhecimento crítico do contexto material e imaterial a projetar, induza ao desenvolvimento de aptidões e competências profissionais.

- Visão - Adquirir a capacidade de ter uma 'visão orgânica' da ação de projeto para restaurar a complexidade dos contextos físicos, históricos, culturais e sociais numa 'visão unitária' e uma 'visão sistémica' atenta à complexa relação e estrutura entre 'o todo' e 'as partes'.

- Método - Adquirir a capacidade de conceber o Desenho Urbano como um processo circular e recursivo que compreenda, de fato, sua inclusão em uma visão / investigação / ensino / projeto / participação.

O enfoque da Missão / Visão / Método se concretiza através do desenvolvimento de uma série de etapas que, gradativamente, conduzem o aluno a um processo de amadurecimento da própria ideia de um espaço de relações, de espaço social, de espaço urbano. Esta metodologia de prática projetual verificada nos Laboratórios de Projeto é ampliada através do suporte de uma pesquisa aplicada que desenvolvi recentemente sobre o tema da cultura do projeto no âmbito do Patrimônio Urbano.

Mencionei acima uma das pesquisas mais recentes que, partindo do tema geral, se concentra em Florença, um Patrimônio Mundial protegido pela Unesco, mas também uma realidade frágil se o projeto de patrimônio 
como 'proteção ativa' não induzir ações para recuperar a sua estrutura semântica, a qual corre o risco de se tornar um ícone cultural, uma marca (brand) de turismo de fachada. A emergência sanitária tem travado este processo, mas se queremos recuperar a identidade desta cidade em termos de sustentabilidade e resiliência, é desejável que os seus fios narrativos sejam encontrados através de interpretações que interajam por relação dinâmica e implementável, com o objetivo de redescobrir um elo entre a cidade física e a cidade dos cidadãos. Devido a isto, é importante, no âmbito de um marco regulatório, uma relação renovada entre as ações de proteção, conservação e valorização, previstas no art. $9^{\circ}$ da Constituição[7] e do Código do Patrimônio Cultural, com responsabilidades internacionais compartilhadas pelo Patrimônio tais como introduzidas pela Unesco.

Especificamente, Florença sofre da relação entre as emergências histórico-artísticas, nas quais há muito se concentraram interesses e intervenções, e o seu tecido, um imenso patrimônio de recursos que, ao mesmo tempo, foi negligenciado ou não considerado parte essencial da uma estrutura física e espacial fundamental. No âmbito do ciclo de iniciativas "Città_Patrimonio e Progetto" "Cidade_Patrimônio e Projeto"), realizouse a Conferência-Mostra-Mesa Redonda sobre o tema das praças menores do Centro Histórico de Florença, que se insere no amplo debate sobre a recuperação e valorização de um patrimônio 'menor' em suas diferentes formas[8].

\begin{abstract}
A hipótese de intervir numa ampla disponibilidade e variedade de lugares, espaços e estruturas menos frequentados e conhecidos (sejam povoados, centros históricos, vias ferroviárias, museus, etc.) surge da convicção de que, através da sua reintegração em uma rede de relacionamentos mais extensa, seja possível ativar processos virtuosos de requalificação e tutela. Nisso há um reconhecimento da importância que eles podem desempenhar na preservação da integridade geral do sistema sociocultural mais amplo. $\mathrm{Na}$ era do sprawl, do turismo de massa hoje universalmente entendido em sua dupla natureza, como fonte de bem-estar econômico mas também como uma ameaça concreta à sobrevivência das especificidades socioeconômicas e culturais, a busca por uma atratividade diversa, baseada em pequenas polaridades museológicas, urbanas, paisagísticas, ambientais, capazes de propor novos circuitos e métodos de uso, são vistas como uma oportunidade de ampliação da oferta cultural e um precioso instrumento de descongestionamento dos principais destinos turísticos, agora em um estado de crise que assume uma dimensão transnacional[9] (Zaffi 2019, p. 271).
\end{abstract}

Basicamente, como arquitetos, tendemos a ler a identidade dos lugares principalmente através de sua expressão construída. Porém a consideração do processo que deu origem a essa forma, a cultura que está subjacente a esse projeto é a memória de sua identidade porque é o resultado de uma forte empatia com os lugares. Expressa também uma intenção que é o desejo de construir uma visão coletiva e a capacidade de ver a cidade em toda a sua dimensão estética, social e cultural, e não como um somatório de situações isoladas, episódios ou questões críticas.

Por isso, voltando ao tema das praças menores em Florença, ao invés de soluções definitivas, optou-se por relacioná-las dentro de um 'sistema serial temático' que, ao oferecer diferentes caminhos de exploração, possa verificar seu potencial como espaços complexos e coordenados capazes de permitir a liberdade de ação, mas também a capacidade de orientação e leitura de um tecido orgânico em que a relação colaborativa entre as partes e o todo amplifica o valor e os recursos do indivíduo. Isto parece ser hoje uma das grandes complexidades a resolver quando se intervém sobre o espaço público.

\title{
4. Conclusões
}

Intervir hoje no corpo da cidade significa antes de tudo respeitar as suas características fundadoras e tentar decliná-las segundo uma sensibilidade contemporânea. A maneira como os arquitetos podem colher a origem da harmonia da cidade histórica é dada pelo desejo de 'sentir' a cidade e 'ouvir' a comunidade na tentativa de reconstruir o equilíbrio entre a urbs e a civitas. Isto sempre alimentou a complexidade das transformações urbanas segundo um princípio de modificação evolutiva, ainda que, desde os últimos vinte anos do século 
passado, aparentemente tenhamos optado por não transformar em um novo Renascimento os recursos que a mudança significativa trazida pela globalização nos oferecia.

Neste sentido, é imprescindível sublinhar a importância de uma Cultura de Projeto a ser refinada, mas igualmente a importância de partilhar boas práticas sobre a Cultura do Patrimônio a partir do desejo de recuperar a capacidade de 'sentir a cidade' e de revalorizar o conhecimento profundo e paciente, como um costume refinado e delicado que amplia esse conhecimento como capacidade interpretativa, para ter a força e a coragem de propor, através do projeto, interpretações diferentes, tal como aprendemos com aqueles que nos precederam, por exemplo, com os homens do Renascimento em Florença. Como parte desta reflexão, o tema das praças menores do centro histórico de Florença representa uma tentativa de reler precisamente este 'tema dentro do tema'. Recurso sustentável que, a partir da convergência entre a preservação e valorização do Patrimônio como herança cultural, se declina como um espaço renovado para contribuir para o bem-estar das comunidades e para a qualidade de vida nos diversos ecossistemas materiais e imateriais.

\section{REFERÊNCIAS BIBLIOGRÁFICAS}

Capanni F. (2019), L'anima della città, in A. Capestro A. (a cura di), Città_Patrimonio e Progetto. Piazze minori nel centro storico di Firenze, Didapress, Firenze, pp. 12-15.

Capestro A. (2010), Renzo Piano. L'architetto e la terra, Firenze Architettura, vol. 2, pp. 58-67.

Capestro A. (2012), Progettando Citta\# - Tematiche di Progettazione Urbana, FUP, Firenze.

Capestro A. (a cura di) (2019), Città_Patrimonio e Progetto. Piazze minori nel centro storico di Firenze, Didapress, Firenze.

Capestro A. (2019), Centro storico di Firenze: il patrimonio delle piazze minori, in A. Calderoni et. al. (a cura di), Il Progetto di architettura come intersezioni di saperi. Per una nozione rinnovata di Patrimonio, ProArch, Napoli, pp. 1736-1741.

Francini C. (2008), The World Heritage Criteria for the Historic Centre of Florence, in A. Tomas- zewski, Values and Criteria in Heritage Conservation, Polistampa, Firenze, pp. 435-438.

Francini C. (2011), Sustainable Tourism and Historic Centre of Florence UNESCO Management Plan, in S. Giometti, A. Tomaszewski (a cura di), The Image of Heritage. Changing Perception, Per-manent Responsibilities, Polistampa, Firenze, pp. 243-248.

Lauria, A. (a cura di) (2017), Piccoli Spazi Urbani. Valorizzazione degli spazi residuali in contesti storici e qualità sociale, Liguori, Napoli.

Calderoni A. et al. (a cura di) (2019), Il progetto di architettura come intersezione di saperi. Per una nozione rinnovata di Patrimonio, ProArch, Napoli.

Palumbo C. (1997), Estetizzazione dell'esperienza urbana, in P. Paoli et al., Metamorfosi urbane. Scenari e progetto, Alinea, Firenze, pp. 16-19.

Romano M. (2008), La citta\# come opera d'arte, Einaudi, Torino.

Sennet R. (2019), L'uomo artigiano, Feltrinelli, Milano.

Sennet R. (2018), Building and dwelling: ethics for the city, Farrar Straus \& Giroux, New York.

Zaffi L. 2019, Il progetto delle piazze minori: indirizzi progettuali, azioni e strumenti, in A. Capestro A. (a cura di), Città_Patrimonio e Progetto. Piazze minori nel centro storico di Firenze, Didapress, Firenze, pp. 271-285.

Zoppi M. C. (2017), Vivere i centri storici, Aska, Firenze.

\section{REFERÊNCIAS - SÍTIOS}

Bokova I. G. (2012), The Opportunity of Urbanization in the 21st Century: The Role of the United Nations, relazione al World Urban Forum, Napoli 2012, https://unesdoc.unesco.org/ ark:/48223/pf0000217523. (09/19). 
CISDU-Centro Internazionale Studi Disegno Urbano, La città/Le città, https://www.youtube.com/channel/ UCl2X6wUO20Hc9-JOZbdvOqQ/videos (12/20).

CISDU-Centro Internazionale Studi Disegno Urbano, Sito web, www.cisdu.org (12/20).

Comune di Firenze, (2018), Rinascimento Metropolitano, Citta\# Metropolitana di Firenze, Piano Strategico 2030, Firenze, http://pianostrategico.cittametropolitana.fi.it/doc/PSM_DOCUMENTO\%20APPROVATO.pdf $(12 / 20)$.

Consiglio d'Europa - (Cets No. 199), Convenzione quadro del Consiglio d'Europa sul valore dell'eredita\# culturale per la società, Faro 2005, http://musei.beniculturali.it/wp-content/uplo- ads/2016/01/Convenzione-di-Faro.pdf (09/19).

Firenze Patrimonio Mondiale, Piano di gestione 2016 http://www.firenzepatrimoniomondiale. it/piano-di-gestione/ (09/19).

UNESCO, https://whc.unesco.org/ (09/19).

UNESCO (2011), Recommendation on the Historic Urban Landscape - Introduction, Punto 3, 36th sessione della Conferenza generale, Parigi 2011, https://whc.unesco.org/uploads/activities/ documents/activity-638-98.pdf $(09 / 19)$.

UNESCO (2013), New life for historic cities. The historic urban landscape approach explained. Introduces the Recommendation on the Historic Urban Landscape, Parigi 2013, https://whc. unesco.org/uploads/activities/ documents/activity-727-1.pdf(09/19).

Cellamare C. (2012), Identità urbane: pratiche, progetto, senso dei luoghi, in Il campo della cultura, http://www.campodellacultura.it/conoscere/approfondimenti/identita-urbane-praticheprogetto-senso-dei-luoghi/ (11/20).

\section{Notas}

[1] UNESCO 2011, Recomendação para a valorização e proteção da Paisagem Urbana Histórica/Recommendation on the Historic Urban Landscape, 36 a sessão da Conferência Geral realizada em Paris em 2011.

[2] Do vídeo "Renzo Piano: l'architetto della luce", direção de Carlos Saura, 2018.

[3] A iniciativa, da qual fui coordenador, é promovida pelo DIDA-Dipartimento di Architettura dell'Universita\# degli Studi di Firenze com DeVisu-Laboratoire Design Visuel et Urbain de l'Universite\# Polytechnique Hauts-de-France; organizada pelo UD-Laboratorio di Urban Design do Dipartimento di Architettura di Firenze e pelo CISDU-Centro Internazionale di Studi sul Disegno Urbano; em colaboração com a Universita\# Cattolica - Nostra Signora del Buon Consiglio, University of Portsmouth, Laboratoire PARAGRAPHE, Firenze Patrimonio Mondiale, FAF-Fondazione Architetti Firenze e OAF-Ordine Architetti Firenze, MAD - Murate Art District, MUS.E - Musei Eventi Firenze, Progetto RIVA, ANCSA; de acordo com SENSI contemporanei, Agenzia per la Coesione Territoriale, MIBACT, Regione Toscana, Fondazione Sistema Toscana, Comune di Firenze.

[4] Os temas propostos pelo programa do Ciclo são diferentes: A Cidade como modelo em crise mas sempre capaz de tornar-se um sistema resiliente; As Cidades, tão generosas em exemplos e declinações em um tecido orgânico de história, contexto e comunidade, imensamente ricas em recursos para repensar em suas múltiplas dimensões; A Comunidade que está descobrindo o caminho da solidariedade como valor agregado e da Participação como oportunidade de intervir na construção da cidade com uma narrativa própria; A Tecnologia como ferramenta de compartilhamento que nos sustenta e nos alimenta em espaços virtuais de ação sem nos privar dos espaços indispensáveis para uma interação real.

[5] Os programas das Conferências do Ciclo La Città/Le Città podem ser consultados na página web do UD-Laboratorio di Urban Design do Departamento de Arquitetura de Florença no link: https://www.dida.unifi.it/vp-627-laboratoriourban-design.html

Os vídeos das Conferências podem ser acessados no canal YouTube do CISDU-Centro Internazionale Studi Disegno Urbano al link: https://www.youtube.com/channel/UCl2X6wUO20Hc9-JOZbdvOqQ/videos

[6] O assunto Dimensions of urban design foi tratado e exposto no contexto da "7th HyperUrban International Conference Modes of Presence in the Postdigital city”. Iniciativa organizada pelo De\# partment des Digital Humanities - Universite\# Paris 8, DeVisu-laboratoire Design Visuel et Urbain - Universite\# Polytechnique Hauts de France, UFRJ-Universidade Federal Rio de Janeiro, Chaire UNESCO ITEN-Innovation Trasmission Sdition Nume\#rique, FMSH-Fondation Maison des Sciences de l'Homme. Rio de Janeiro 30/31 ottobre 2019. 
[7] "A República promove o desenvolvimento da cultura e da pesquisa científica e técnica. Protege a paisagem e o patrimônio histórico e artístico da nação ".

[8] No triênio 2018/2020 o DIDA-Departamento de Arquitetura de Florença e il CISDU-Centro Internazionale di Studi sul Disegno Urbano em colaboração com a Prefeitura Municipal de Florença- Ufficio Unesco promoveu o ciclo de iniciativas Cittȧ_Patrimonio e Progetto para chamar a atenção de representantes de órgãos públicos e privados, instituições culturais e de pesquisa, entidades de classe, categorias produtivas e sociais para o desafio do tema destacado no título da iniciativa. Partindo do pressuposto, aliás destacado em vários níveis, de que os desafios que a sociedade contemporânea coloca requerem estratégias e ferramentas de implementação importantes e necessárias para enfrentar de forma consciente o processo de transformações em curso, o que se quis sublinhar com este ciclo foi a reflexão sobre a necessidade de uma cultura de projeto a ser integrada em uma estrutura de operações compartilhadas. O primeiro tópico tratado foram as Praças Menores no Centro Histórico de Florença.

[9] Essas considerações, agora de domínio internacional, também foram aceitas no Plano Estratégico da Área Metropolitana Florentina 2030: "O objetivo fundamental (do Plano) é explicitar o variegado patrimônio cultural, agrícola e ambiental, material e imaterial, estendido ao longo de 'todo o território, mostrando os recursos já ativos e suas potencialidades”. Complementando ainda: "As infraestruturas culturais mais importantes (museus, igrejas, edifícios históricos, teatros, etc.) terão de se transformar em portas de acesso a outros territórios e a formas de turismo que não as tradicionais, como o turismo sustentável (cicloturismo, percursos naturais, parques, etc.) e / ou que privilegia locais menos frequentados (povoados, zonas rurais, pequenas cidades, etc.)” (Comune di Firenze, 2018, p. 95).

* Texto original em italiano, traduzido pela Profa. Dra Carla Cipolla, Universidade Federal do Rio de Janeiro (UFRJ).

\section{INFORMACIÓN ADICIONAL}

Tradução: Profa. Dra. Carla Cipolla da Universidade Federal do Rio de Janeiro. 